\title{
Calcium homeostasis
}

\section{N Manitshana}

Department of Anaesthesiology, Charlotte Maxeke Johannesburg Academic Hospital, University of the Witwatersrand, South Africa Corresponding author, email: nontsikelelo.manitshana@wits.ac.za or drntsiki@live.com

Keywords: calcium, homeostasis, cholecalciferol, parathyroid hormone

Calcium and phosphorus are the most abundant minerals in the body. An adult body contains over $1 \mathrm{~kg}$ of calcium and it has various functions throughout the body. The average plasma concentration of calcium is about $2.5 \mathrm{mmol} / \mathrm{l}$. The intracellular concentration of calcium is approximately $100 \mathrm{nmol} / \mathrm{ml}$. The control of both intracellular and extracellular calcium concentrations is vital. ${ }^{1,2}$

Ninety-nine per cent of the calcium is stored in the body as hydroxyapatite crystals $\left(\mathrm{Ca}_{5}\left(\mathrm{PO}_{4}\right)_{3} \mathrm{OH}\right)$ found in bone. This reflects its importance in the structural integrity of the skeletal system. This forms the non-readily exchangeable pool, i.e. not available for rapid mobilisation. The remaining $1 \%$ is found distributed between the ECF (extracellular fluid) and the intracellular fluid (ICF). These are considered as the readily exchangeable pool. ${ }^{3}$

This $1 \%$ is further distributed into the diffusible and nondiffusible fractions. The non-diffusible fraction constitutes $45 \%$ of this readily exchangeable pool and refers to the calcium that is bound to proteins, namely albumin and globulin. The diffusible fraction ( $55 \%$ of the readily exchangeable pool) is further divided into ionised calcium and complexed calcium. Complexed calcium comprises $10 \%$ of this diffusible fraction and is complexed to $\mathrm{HCO}_{3}{ }^{-}$, citrate or hydrogen phosphate. The ionised calcium or free calcium forms $45 \%$ of this diffusible fraction.

Basically, calcium in the readily exchangeable pool can be found in three forms:

\section{Distribution Of Calcium}

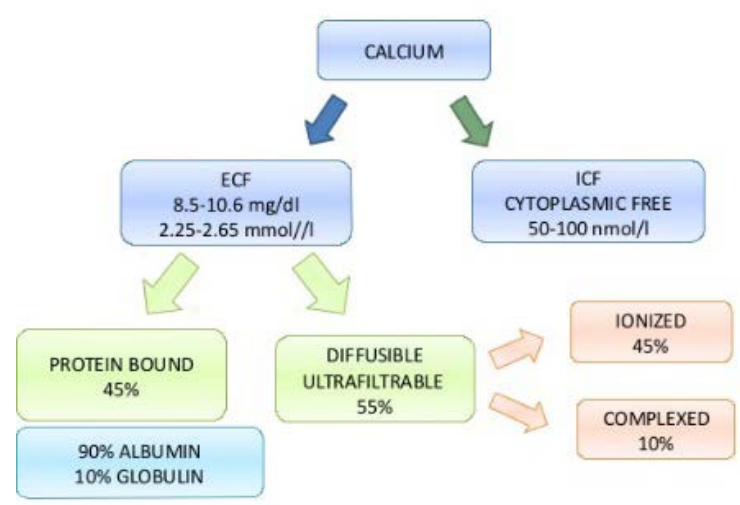

Figure 1: Distribution of calcium ${ }^{4}$
a) protein bound
b) complexed
c) ionised

It is this free (ionised) calcium $\left(\mathrm{Ca}^{2+}\right)$ that is measured in the blood and is also a vital second messenger for its own homeostasis and various other bodily functions. ${ }^{5,6}$

The functions of calcium are:

- Second messenger functions

- Nerve impulses (essential for release of neurotransmitters)

- Membrane excitation

- Muscle contraction

- Coagulation

- Gene expression

- Structural support

- Excitation and secretion processes

For all these processes to occur, calcium receptors and calcium channels are required. The calcium-sensing receptors (CaSRs) are essential for calcium homeostasis, and the calcium channels (ligand-gated and voltage-gated channels) are essential for the extracellular and intracellular effects initiated by calcium.

Below are a few basics on the second messenger functions, because they play a major role in calcium homeostasis.

For intracellular communication to occur, there are receptors that have specific ligands designed specifically for them. There are many types of these receptor-ligand pairs. The receptors are classified into two types: intracellular or extracellular (cell-surface) receptors. There are various types of extracellular receptors, the three most common are: ligand-ion gated, G-protein coupled and enzyme-linked receptors (tyrosine-kinase linked). Their various ligands may be in the form of proteins, steroids, ions or even gases, such as nitric oxide.

The binding of ligands to these extracellular receptors results in three possible effects:

- Opening of ionic channels (aka ionotropic)

- Activation of G-proteins (aka metabotropic)

- Direct catalysis of substrates (aka catalytic enzyme-linked aka Tyrosine Kinase-linked receptors) 
Summary: Extracellular ligands are called first messengers and the intracellular mediators are called second messengers. Second messengers promote short term changes in the cell function by altering enzyme function, initiating exocytosis and altering RNA transcription. The second messengers bind to the intracellular receptors (intracellular calcium receptors are the ryanodine and dihydropyridine receptors). ${ }^{?}$

So, calcium is a ligand that binds to both intracellular and extracellular receptors. There are calcium-sensing receptors (CaSR) and calcium channels, found on the cell membrane, extracellularly.

The calcium concentration $\left(\left[\mathrm{Ca}^{2+}\right]\right)$ in the ECF is much higher than in the ICF, therefore there is an inwardly directed electrical and concentration gradient. High intracellular $\left[\mathrm{Ca}^{2+}\right]$ can be toxic to cells; therefore its tight regulation is necessary. The intracellular $\left[\mathrm{Ca}^{2+}\right]$ is tightly regulated via various calcium ion channels, pumps and binding proteins. The intracellular $\mathrm{Ca}^{2+}$ is stored in the endoplasmic reticulum and other cell organelles. This calcium can be mobilised when the CaSR is stimulated and can increase the concentration of calcium in the cytoplasm via the second messenger system. This calcium mobilisation then results in the binding of $\mathrm{Ca}^{2+}$ to calcium-binding proteins (such as troponin, calmodulin and calbindin) which in turn bring about different physiological effects. An excess of intracellular $\mathrm{Ca}^{2+}$ results in activation of the ATPases which provide energy to the $\mathrm{Na}^{+} / \mathrm{Ca}^{2+}$ antiporter which removes calcium in exchange for sodium (energy is required for this extrusion of calcium because it has to move against the concentration gradient). There are two such ATP dependent pumps, namely $\mathrm{Ca}^{2+} / \mathrm{H}^{+}$exchanger and the $\mathrm{Na}^{+} / \mathrm{Ca}^{2+}$ exchange pump. The pump with the highest capacity is the $\mathrm{Na}^{+} / \mathrm{Ca}^{2+}$ exchange pump which exchanges three $\mathrm{Na}^{+}$for each $\mathrm{Ca}^{2+}$ removed. This is how the tight intracellular calcium concentration is maintained; provided there is enough ATP to maintain the integrity of the pumps. ${ }^{1,8-10}$

The other second messengers, such as IP3 and cyclic AMP, stimulate release of calcium from the endoplasmic reticulum. The calcium that is released takes on second messenger functions itself and triggers further opening of the calcium channels. This results in a rapid increase in calcium within the cytosol. The movement of calcium affects the electrochemical gradients, therefore also requires energy. ${ }^{6}$

\section{The calcium receptor}

The CaSR is a plasma membrane G-protein coupled receptor that is expressed on the parathyroid gland cells and the renal tubular cells. It is classified as a Thyrotropin-type G-Protein receptor. It can also be found on the intestines and on the thyroid cells. Ionised calcium acts on the CaSR found on the parathyroid glands to inhibit release of parathyroid hormone (PTH). The CaSR detects the extracellular plasma levels of calcium and therefore controls calcium reabsorption within the kidneys, calcium absorption in the intestines and calcium resorption in bone. ${ }^{1}$

$\left[\mathrm{Ca}^{2+}\right]$ activates two G-protein signalling pathways:

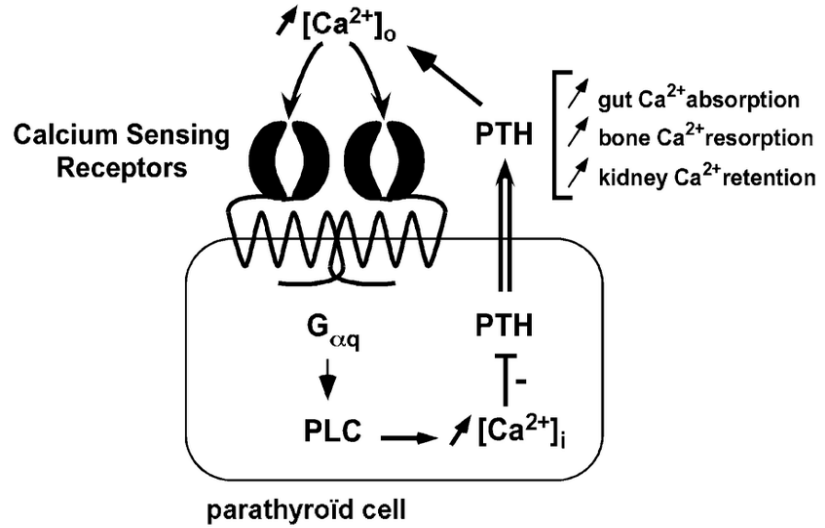

Figure 2: Calcium-sensing receptors on parathyroid cells ${ }^{6}$

- Gq leading to release of phospholipase C which mobilises intracellular calcium from the endoplasmic reticulum, and

- the Gi/o pathway inhibits adenylate cyclase, therefore reducing CAMP and protein kinase activity, leading to changes in gene transcription. ${ }^{4,6}$

\section{Calcium channels: $\mathrm{T}, \mathrm{N}$ and L types}

The calcium channel consists of four high-molecular weight subunits: $a 1, a 2, \beta$ and $\gamma$. This complex structure of four domains is made up of six transmembrane units each. They are either ligand-gated or voltage-gated channels. Voltage-gated calcium channels are an essential part of membrane excitation and propagation of the action potential. There are $L, N, P Q, R$ and T-type calcium channels:

- L-type (long-lasting) channels found in the cardiovascular system (CVS) are essential for the plateau phase of the cardiac action potential. They are also the target of anti-hypertensives via the dihydropyridine receptors. They are also important for the excitation-secretion in endocrine cells.

- T-type (transient) channels. Of all the $\mathrm{Ca}^{2+}$ channels, they take the longest to deactivate.

- N-type (neuronal) channels are essential for neurotransmitter release. They are the target for drugs altering neuropathic pain, such as the gabapentanoids.

- PQ-type (Purkinje) channels are also found in the CVS and mediate depolarisation-induced spikes..$^{6,11}$

\section{Homeostasis}

Calcium homeostasis is dependent on three hormones: calcitonin, vitamin D (cholecalciferol) and parathyroid hormone (PTH). These hormones act on bone (osteoclasts, osteoblasts and osteocytes) for bone formation and resorption, the intestines for dietary calcium reabsorption and the kidneys also calcium reabsorption. ${ }^{1,12,13}$ In an effort to maintain stable calcium concentrations, the body sacrifices its structural integrity (hence the development of osteoporosis), when faced with hypocalcemia. This is because calcium is an essential substrate in many physiological processes. 


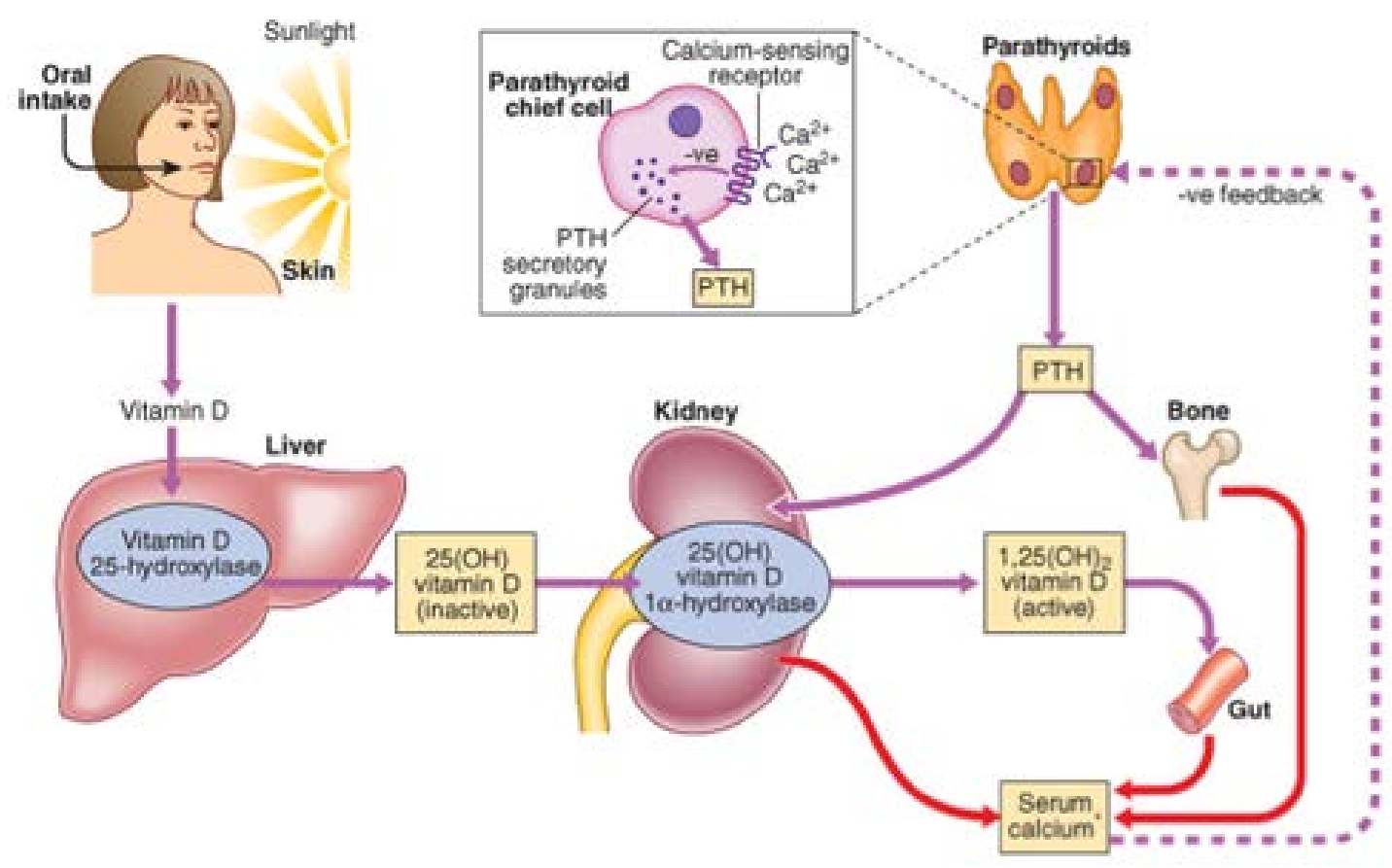

Figure 3: Parathyroid hormone regulation ${ }^{14}$

When there is hypocalcemia, the CaSRs on the parathyroid glands are stimulated via G-protein mediated processes.

This results in the PTH-filled secretory granules fusing with the cell membrane and their contents being released into the circulation. This circulating PTH then increases bone resorption and renal reabsorption of $\mathrm{Ca}^{2+}$. This process is regulated by a negative feedback mechanism, in which the parathyroid gland then reduces PTH secretion (via the CaSR), once $\left[\mathrm{Ca}^{2+}\right]$ levels are restored.

The majority of $\mathrm{Ca}^{2+}$ absorption occurs in the GIT (gastrointestinal system) through active and passive mechanisms, stimulated by 1.25 dihydroxycholecalciferol (active vitamin $\mathrm{D}: 1.25 \mathrm{Di}(\mathrm{OH})_{2}$.) Dietary $\mathrm{Ca}^{2+}$ is transported across the intestinal epithelium brush border via the transient receptor potential vanilloid type $6\left(\mathrm{TPRV}_{6}\right)$ channels. The expression of these TPRV channels is controlled by PTH but regulated by $1.25 \mathrm{Di}(\mathrm{OH})_{2}$. The intracellular $\mathrm{Ca}^{2+}$ has to be bound to calbindin in order to prevent interference with other intracellular signalling within the intestinal cells. It is then transported into the circulation via the $\mathrm{Na}^{+} / \mathrm{Ca}^{2+}$ exchange pump. This movement of $\mathrm{Ca}^{2+}$ from the intestinal epithelium into the circulation is regulated by $1.25 \mathrm{Di}(\mathrm{OH})_{2}{ }^{1}$

The CaSRs on the kidney promote reabsorption of $\mathrm{Ca}^{2+}$ from the proximal tubule, as well as in the thick ascending loop of Henle and distal tubules. This is controlled by PTH, $1.25 \mathrm{Di}(\mathrm{OH})_{2}$ and oestrogen. The $\mathrm{Ca}^{2+}$ channels in the kidney are also from the TPRV family, but unlike the GIT, these are the TPRV ${ }_{5}$ channels. They promote the transportation of $\mathrm{Ca}^{2+}$ across the luminal membrane of the kidney. The $\mathrm{Ca}^{2+}$ then also binds to calbindin proteins, until its transportation across the basolateral membrane into the circulation.

PTH not only promotes synthesis of $1.25 \mathrm{Di}(\mathrm{OH})_{2}$ in the proximal tubules, but also the production of 1a-hydroxylase, which is required for the conversion of 25-hydroxycalciferol (inactive vitamin $\mathrm{D}$ ) into $1.25 \mathrm{Di}(\mathrm{OH})_{2}$.

The skeletal system is the third $\mathrm{Ca}^{2+}$ regulation organ. Osteoblasts are important for bone formation and osteoclasts are essential for bone demineralisation and mobilisation of $\mathrm{Ca}^{2+}$.

PTH and $1.25 \mathrm{Di}(\mathrm{OH})_{2}$ regulate $\mathrm{Ca}^{2+}$ resorption in bone by activating osteoclasts via the receptor activator of nuclear $F$ factor-k $\beta$ ligand (RANKL). ${ }^{1,4,6}$

\section{Parathyroid hormone}

- Produced by four small parathyroid glands located on the superior and inferior poles of the thyroid. The glands have chief cells which produce PTH.

- PTH is an 84 amino acid polypeptide, that begins as preproPTH, which with further synthesis becomes proPTH, which is finally cleaved into PTH, which is stored in secretory granules in the chief cells. ${ }^{6}$

Its regulation is controlled by extracellular $\left[\mathrm{Ca}^{2+}\right]$ : the lower the ionised $\mathrm{Ca}^{2+}$, the higher the PTH and vice versa. The CaSRs of the parathyroid gland are stimulated by fluctuations in the extracellular circulating $\mathrm{Ca}^{2+}$ and $\beta$-adrenergic stimulation. High plasma $\mathrm{Ca}^{2+}$ binds to CaSR and activates $\mathrm{Gq}$ (G-protein coupled receptor as discussed above) and this reduces PTH secretion.

PTH raises plasma calcium by:

1. Increasing bone resorption by activating osteoclastic activity.

2. Increasing renal calcium reabsorption by the distal renal tubules.

3. Increasing renal phosphate excretion by decreasing tubule phosphate reabsorption.

4. Increasing the formation of $1.25 \mathrm{Di}(\mathrm{OH})_{2}$ by increasing the activity of 1a-hydroxylase in the kidney. 


\section{Vitamin D}

It is a steroid compound derived from cholecalciferol (vitamin $D_{3}$ ). Sunlight promotes its synthesis in the skin from 7-dehydrocholesterol. Its synthesis in the liver involves hydroxylation (via 25-hydroxylase) of cholecalciferol to 25-hydroxycalciferol, which is then converted in the kidneys, by renal 1-a hydroxylase into $1.25 \mathrm{Di}(\mathrm{OH})_{2}$. PTH stimulates this conversion of inactive cholecalciferol into its active metabolite, $1.25 \mathrm{Di}(\mathrm{OH})_{2}$, which is crucial for synthesis of calbindin-D proteins for calcium transport across the renal and intestinal epithelium. $1.25 \mathrm{Di}(\mathrm{OH})_{2}$ also increases the expression of renal TPRV ${ }_{5} \mathrm{Ca}^{2+}$ reabsorption at the proximal tubules occurs via a negative feedback mechanism, where if the plasma $\left[\mathrm{Ca}^{2+}\right]$ is elevated, the production of $1.25 \mathrm{Di}(\mathrm{OH})_{2}$ is reduced via a reduction in PTH secretion and thus less expression of TPRV type 5 for renal reabsorption. However, when the plasma $\left[\mathrm{Ca}^{2+}\right]$ is low, PTH secretion increases the expression of renal 1-a hydroxylase and therefore increases the conversion of 25 -hydroxycalciferol to $1.25 \mathrm{Di}(\mathrm{OH})_{2}$.

The quantity of CaSRs present on organs is determined by 1.25 dihydroxycholecalciferol $\left(1.25 \mathrm{Di}(\mathrm{OH})_{2}\right)$ and not by calcium. The $1.25 \mathrm{Di}(\mathrm{OH})_{2}$ is thus found in parathyroid, kidney and thyroid cells.

\section{Calcitonin}

It is a 32 amino-acid chain, secreted by the thyroid parafollicular $C$ cells when the plasma $\left[\mathrm{Ca}^{2+}\right]$ rises above $2.4 \mathrm{mmol} / \mathrm{l}$. The CaSRs on these parafollicular cells stimulate them to secrete calcitonin when $\mathrm{Ca}^{2+}$ binds to them. Calcitonin lowers $\left[\mathrm{Ca}^{2+}\right]$ and phosphate levels by reducing renal reabsorption of phosphate and $\mathrm{Ca}^{2+}$ (therefore increasing renal excretion). It also reduces the mobilisation of $\mathrm{Ca}^{2+}$ from bone by directly inhibiting osteoclasts. Other hormones that increase calcitonin secretion include gastrin, $\beta$-adrenergic agonists, oestrogen and dopamine.

\section{Conclusion}

The three main hormones that control $\mathrm{Ca}^{2+}$ regulation include $\mathrm{PTH}$, calcitonin and $1.25 \mathrm{Di}(\mathrm{OH})_{2}$. Calcitonin has $\mathrm{Ca}^{2+}$ lowering effects whereas PTH and 1.25 $\mathrm{Di}(\mathrm{OH})_{2}$ have $\mathrm{Ca}^{2+}$ elevating effects.

\section{Conflict of interest}

The author declares no conflict.

\section{Funding source}

None.

\section{ORCID}

N Manitshana (iD https://orcid.org/0000-0002-8264-9916

\section{References}

1. Pu F, Chen N, Xue S. Calcium intake, calcium homeostasis and health. Food Science and Human Wellness. 2016;5(1):8-16. https://doi.org/10.1016/j. fshw.2016.01.001

2. Siyam FF, Klachko DM. What is hypercalcemia? The importance of fasting samples. Cardiorenal Medicine. 2013;3(4):232-8. https://doi. org/10.1159/000355526

3. Veldurthy $\mathrm{V}$, Wei $\mathrm{R}, \mathrm{Oz} \mathrm{L}$, et al. Vitamin $\mathrm{D}$, calcium homeostasis and aging. Bone research. 2016;4:16041. https://doi.org/10.1038/boneres.2016.41.

4. Kam P, Power I. Principles of physiology for the anaesthetist: calcium metabolism. In: Kam P, Power I, Siddal P, Cousins M, editors. Principles of physiology for the anaesthetist. 3rd ed. New South Wales, Australia: CRC Press; 2015. p. 342-5.

5. Endo M. Calcium ion as a second messenger with special reference to excitation contraction coupling. J Pharmacol Sci. 2006;100(5):519-24. https://doi org/10.1254/jphs.cpj06004x.

6. Barrett K, Barman S, Boitano S, Brooks H. Hormonal control of calcium and phosphate metabolism. In: Weitz M, Brown R, editors. Ganong's Review of medical physiology. 23rd ed. San Francisco, California, USA: McGraw-Hill Lange; 2010. p. 363-71.

7. Zhang C, Miller $\mathrm{CL}$, Brown $\mathrm{EM}$, Yang JJ. The calcium sensing receptor: from calcium sensing to signaling. Sci China Life Sci. 2015;58(1):14-27. https://doi. org/10.1007/s11427-014-4779-y.

8. Kleeman CR, Massry SG, Coburn JW. The clinical physiology of calcium homeostasis, parathyroid hormone, and calcitonin. Calif Med. 1971;114(3):16-43.

9. Talmage RV, Mobley HT. Calcium homeostasis: reassessment of the actions of parathyroid hormone. Gen Comp Endocrinol. 2008;156(1):1-8. https://doi. org/10.1016/j.ygcen.2007.11.003.

10. Krebs J, Agellon LB, Michalak M. Ca(2+) homeostasis and endoplasmic reticulum (ER) stress: an integrated view of calcium signaling. Biochem Biophys Res Commun. 2015;460(1):114-21. https://doi.org/10.1016/j.bbrc.2015.02.004.

11. Murer $\mathrm{H}$, Hernando $\mathrm{N}$, Forster I, Biber J. Molecular mechanisms in proximal tubular and small intestinal phosphate reabsorption (Plenary Lecture). Mol Membr Biol. 2001;18(1):3-11. https://doi.org/10.1080/09687680010019357.

12. Brown EM. Physiology and pathophysiology of the extracellular calcium sensing receptor. Am J Med. 1999;106(2):238-53. https://doi.org/10.1016/ S0002-9343(98)00418-5.

13. Mundy GR, Guise TA. Hormonal control of calcium homeostasis. Clin Chem 1999;45(8):1347-52. https://doi.org/10.1093/clinchem/45.8.1347.

14. Haslett C, Boon N, Colledge N. Davidson's principles and practice of medicine. 19th ed. Edinburgh, United Kingdom: Churchill Livingstone; 2002. p. 714-6. 